\title{
Metagenomic analysis of the bacterial microbiota linked to the traditional Algerian date product "Btana"
}

\author{
Abdelkader Abekhti ${ }^{1,2,3} \cdot$ Bernard Taminiau $^{1} \cdot$ Mabrouk Kihal $^{2} \cdot$ Georges Daube $^{1}$
}

Received: 23 October 2014 / Accepted: 1 April 2015

(C) Springer-Verlag Berlin Heidelberg and the University of Milan 2015
Keywords Pyrosequencing $\cdot$ Bacterial diversity $\cdot$ Traditional food $\cdot$ Dates $\cdot$ Phoenix dactylifera $L \cdot B$ tana

\section{Introduction}

Traditional food products play an important role in the diet of local populations in many countries around the world. These products are a major source of valuable nutrients, growth factors, and other health benefits, and are symbolic attributes of many ethnic groups as well (Schoustra et al. 2013). There has been recent continued interest in these foods, as evidenced by an increasing number of published papers and many coordinated national and international projects (Bonomo et al. 2010). Traditional African and Asian products are the most studied, owing to the rural populations who usually prepare vegetables (fruits and legumes), meat, and milk using wellknown traditional methods passed down through generations (Chang et al. 2008; Obadina et al. 2009; Oguntoyinbo and Narbad 2012; Greppi et al. 2013). These practices ensure a stable food supply for local populations during lengthy food shortages. Btana is a traditional date product produced in southern Algeria, especially in the regions of Ziban (Biskra), Oued Righ, Adrar, and Beni Abbas. The product is both consumed at home and commercialized in the southern region of Algeria, and can be preserved for more than 2 years without any visible spoilage. In the past, this product was almost the only food available to honour voluntary workers, to welcome guests and to serve as subsistence during long periods of travel. Btana is normally served with fermented milk (leben), for a complete and high-energy meal. Btana is prepared by compressing dates (Phoenix dactylifera L.) in cotton or plastic sheets - or, in the past, in clean sheepskin, from which the word "Btana" is derived. In general, two methods are applied for Btana preparation (Supplementary Fig. S1). The direct 
Btana method (DBM) is practiced in southeast Algeria (Ziban, Ghardaia, Oued Most pitfalls for microbial diversity studies arise from low DNA yield, low purity, and degradation, which lead to inaccurate information regarding diversity richness (Thakuria et al. 2008). DNA extraction has thus been highlighted as a limitation in culture-independent methods (Abriouel et al. 2006). Choosing an extraction technique often involves a trade-off between cost (materials and labor), optimal DNA yield, and the removal of substances that could interfere with polymerase chain reaction (PCR) (SánchezHernández and Gaytán-Oyarzún 2006). Like other fruits, the date presents many challenges for DNA extraction due to its complex composition and the presence of a broad range of polysaccharides, carbohydrates, polyphenols, and fibers, and high salt content, which can interfere with enzymatic and chemical reactions during DNA extraction or PCR analysis (Boudries et al. 2007; Vayalil 2012). Here, we applied a modified CTAB_cetyltrimethylammonium bromide) protocol to extract bacterial DNA from the Btana product. DNA extracts were subjected to high-throughput pyrosequencing analysis to investigate the diversity of bacterial communities in direct (DBM) and indirect (UBM) Btana products.

\section{Material and methods}

Btana samples were collected from the Zibane, Elmeghier, and Adrar regions based on the method of preparation and potential zone of production. The Ziban and Elmeghier samples were produced by the DBM method, whereas samples from Adrar were produced by the UBM method. Ten grams of each sample was used for $\mathrm{pH}$ and water activity (aw) measurement (Abekhti et al. 2013). Next, 25-g samples were homogenized in sterile bags with $225 \mathrm{ml}$ of alkaline phosphate buffer using a Stomacher apparatus. One milliliter of homogenate was used for counting the total microbial colony at $30{ }^{\circ} \mathrm{C}$ using plate count agar (PCA). Subsequently, $1.5 \mathrm{ml}$ of each sample was centrifuged for $10 \mathrm{~min}$ at $14,000 \mathrm{rpm}$ to harvest bacterial cells for DNA extraction.

\section{CTAB Protocol (modified by Probeski et al. 1997)}

The extraction buffer contained $100 \mathrm{mM}$ Tris, $\mathrm{pH} 8,1.4 \mathrm{M}$ $\mathrm{NaCl}, 30 \mathrm{mM}$ EDTA, $\mathrm{pH} 8,2 \%$ of polyvinylpyrrolidone (PVP) and $2 \%$ of CTAB (Sigma-Aldrich Corp., St Louis, MO, USA), $40 \mathrm{mg} / \mathrm{ml}$ of lysozyme, $1 \%(v / v)$ of bmercaptoethanol, and $2 \mu \mathrm{l}$ of bovine serum albumin (BSA). The buffer was preheated $\left(56^{\circ} \mathrm{C}\right)$ and added $(500 \mu \mathrm{l})$ to the pellet, then homogenized by vortexing for $5 \mathrm{~s}$. Microtubes were then incubated at $56^{\circ} \mathrm{C}$ for $1 \mathrm{~h}$. The lysis was followed by grinding, as described above. Then, $20 \mu$ of Proteinase $\mathrm{K}$ was added to the pellet and incubated at $56^{\circ} \mathrm{C}$ for $1 \mathrm{~h}$. The solution obtained was centrifuged (12,000 rpm) for $5 \mathrm{~min}$. The supernatant was then cooled to room temperature, overlapped with $1 \mathrm{~V}$ isoamyl alcohol:chloroform (1:24) and mixed. The aqueous phase was recovered after centrifugation, treated with $0.5 \mathrm{~V}$ of $5 \mathrm{M} \mathrm{NaCl}$, precipitated with $2 \mathrm{~V}$ of absolute cold 100 $\%$ ethanol $\left(-20^{\circ} \mathrm{C}\right)$ and stored at $-20^{\circ} \mathrm{C}$ for $10 \mathrm{~min}$. Afterwards, the crude DNA pellet was recuperated by centrifugation (12,000 rpm for $5 \mathrm{~min})$ and washed with $200 \mu \mathrm{l}$ of cold $70 \%$ ethanol, then resuspended in sterile RNA-free water.

\section{DNA purification}

The extracted DNA samples were purified with the genomic DNA-cleanup NucleoSpin kit (Macherey-Nagel GmbH \& Co., Düren, Germany), according to the manufacturer's recommendations.

\section{DNA recovery}

The concentration and purity of extracted DNA samples were determined by the A260/A280 ratio, PCR amplification of 16S ribosomal RNA rRNA) gene, and agarose gel electrophoresis. Repeated measures analysis of variance (ANOVA) were used to compare the effect of purification on DNA quality and yield. Statistical analyses were performed using GraphPad Prism 5.01 software.

\section{PCR reactions}

For amplification of the 16S rRNA, 20- $\mu$ l volumes each containing the following were used: $2 \mu \mathrm{l}$ extracted DNA, $2 \mu \mathrm{l}$ of dNTPs $(2 \mathrm{mM}), 1.6 \mu \mathrm{l}$ of MgCl2 $(25 \mathrm{mM}), 2 \mu \mathrm{l}$ of PCR buffer $(10 \times), 0.8 \mu \mathrm{l}$ of each primer $(10 \mu \mathrm{M}) 16 \mathrm{~S}-1500 \mathrm{~F}: 5^{\prime}$ - A-GTTTGA-TCC-TGG-CTC-AG3' $\left(3968107, \mathrm{Tm}=60^{\circ} \mathrm{C}\right.$; Eurogentec S.A., Seraing, Belgium) 16S-1500 REV: 5'TAC-GGT-TAC-CTTGTTACGAC-3' $\left(3968108 \mathrm{Tm}=58^{\circ} \mathrm{C}\right.$; Eurogentec) and $0.2 \mu \mathrm{l}$ of Taq DNA polymerase $(2.5 \mathrm{U}$, FastStart, Roche Diagnostics, Mannheim, Germany) and $2 \mu \mathrm{l}$ of BSA (Invitrogen, Waltham, MA, USA). The PCR program was performed with a Mastercycler gradient (Eppendorf, Westbury, NY, USA) under the following conditions: initial denaturation at $94^{\circ} \mathrm{C}$ for $5 \mathrm{~min}, 35$ cycles at $94^{\circ} \mathrm{C}$ for $30 \mathrm{~s}, 56^{\circ} \mathrm{C}$ for $30 \mathrm{~s}$, and $72^{\circ} \mathrm{C}$ for $1 \mathrm{~min}$, with a final extension at $72^{\circ} \mathrm{C}$ for $5 \mathrm{~min}$.

16S rRNA gene library preparation for metagenomic analysis The gene library was constructed by amplifying the 16S rRNA gene from each Btana sample by targeting the V1V3 regions with the primer pair E9-29 F and E514-430 R 
(Brosius et al. 1981). Each primer was tagged with common titanium adapters (A or B) and sample-specific multiplex identifiers (MIDs) linked to the $5^{\prime}$ end of the each primer. PCR reactions were carried out according to Delcenserie et al. (2014) in a final volume of $100 \mu$ containing $5 \mathrm{U}$ of FastStart high-fidelity polymerase (Roche Diagnostics Belgium NV), $1 \times$ enzyme reaction buffer, $200 \mu \mathrm{M}$ of dNTP mix (Eurogentec S.A., Seraing, Belgium), $0.2 \mu \mathrm{M}$ of each primer, and $100 \mathrm{ng}$ of template DNA. The PCR reactions were performed in a Mastercycler ep gradient apparatus (Eppendorf), with the following program: an initial denaturation for $15 \mathrm{~min}$ at $94^{\circ} \mathrm{C}$, followed by 25 cycles of denaturation at $95^{\circ} \mathrm{C}$ for $40 \mathrm{~s}$, annealing at $56^{\circ} \mathrm{C}$ for $40 \mathrm{~s}$, and extension at $72^{\circ} \mathrm{C}$ for $1 \mathrm{~min}$, and a final extension step at $72^{\circ} \mathrm{C}$ for 7 min (Delcenserie et al. 2014). PCR products were then run on a $1 \%$ agarose electrophoresis gel, and the DNA fragments were extracted and purified with the Wizard SV PCR purification kit (Promega Corporation, Belgium). Then they were quantified by a PicoGreen double-stranded DNA (dsDNA) assay with a fluorimeter (Isogen Life Science NV) and equal amounts of each of the 11 PCR products were pooled together and subsequently amplified by emulsion PCR.

Pyrosequencing analysis Pyrosequencing was performed with the 454 GS Junior sequencer (Roche Diagnostics, Mannheim, Germany) according to the manufacturer's instructions. The sequencing reads from the different Btana samples were analysed using the MOTHUR package developed by Schloss et al. (2009). The sequences were trimmed and sorted according to their multiplex identifier (barcode). The Pyronoise algorithm (Quince et al. 2009) was used to remove reads of low quality, i.e., sequences shorter than 425 bps and containing more than 1 ambiguous base (Ns), and sequences with a homopolymeric track longer than 8 bases were also removed. The sequences were aligned with the SILVA reference database (Pruesse et al. 2007) followed by removing potential chimeric sequences using the chimera.slayer command (Haas et al. 2011) implemented in the MOTHUR package. Finally, the remaining sequences were clustered into OTUs using the nearest neighbour algorithm with a 0.03 distance cut off and taxonomically assigned by comparisons against the SILVA database using the BLASTN algorithm with an $80 \%$-homogeneity cut off.

\section{Statistical analysis}

OTU clusters were used to calculate the Shannon-Weaver diversity index (Shannon and Weaver 1963), the inverted Simpson's evenness index, the Chaol and ACE estimates of richness (Chao and Bunge 2002), and to generate a rarefaction curve for each sample (Colwell and Coddington 1994). The estimated Good's coverage was also determined (Good 1953).
The Btana parameters (age, aw, pH, PCA) were analysed to determine their correlation with community variation. An OTU-based comparison was performed using the BrayCurtis distance between the micro flora to compare the overall bacterial communities of the Btana samples according to their origin and preparation methods (DBM or UBM). Results were then visualized by three axes non-metric multidimensional scaling (nMDS) plots (Schloss et al. 2009). We also assessed the relative contribution of the OTUs to the sample's distribution along the axes.

One-way ANOVA was performed to assess differences in the Btana parameters and differences in the biodiversity index. Nonparametric Kruskal-Wallis one-way ANOVA by rank was applied to verify differences in the relative abundance of the phylogenetic bacterial groups among the studied samples using XLSTAT 2007 software (Addinsoft, Brooklyn, NY, USA). Other statistical analyses were performed with MOTHUR, STAMP and R programs.

\section{Results}

\section{Characteristics of the Btana}

Btana samples were found to be acidic, with $\mathrm{pH}$ ranging between 4.67 to 6.15. The ANOVA one-way analysis $(P>0.05)$ did not show any significant difference between the characteristics of the samples. However a negative correlation was observed between age and aw $(\mathrm{r}=-0.65, P=0.05)$. No association was found between the characteristics of the Btana and its preparation method; however, the lowest $\mathrm{pH}$ values were recorded for the Btana prepared by the UBM method in the Adrar region.

Information about the Btana samples, origin of sampling, age, aw, $\mathrm{pH}$ and microbial loads on PCA are summarized in Table 1.

The CTAB protocol recorded a DNA concentration ranging from $18.80 \mathrm{ng} / \mu \mathrm{l}$ to $437 \mathrm{ng} / \mu \mathrm{l}$, which varied strongly among the samples $(P<0.05)$. A great loss $(55.65 \%)$ of DNA yield was observed after purification, as determined by an ANOVA matched pairs test $(P<0.05)$. The A260/A280 ratio was slightly increased after purification, leading to an improvement in amplification and signal intensity.

\section{Taxonomic profile of the bacterial community (community composition)}

\section{Sequence analysis}

A total of 103,379 reads were generated in a single pyrosequencing run from the $1116 \mathrm{~S}$ rRNA libraries. The quality control parameters yielded 44,852 high quality sequences which also included the plant chloroplast and the plant 
Table 1 Btana sample parameters. PCA counts and DNA concentration

\begin{tabular}{llllll}
\hline Samples & Origin & Age (months) & aw & pH & PCA (CFU/g) \\
\hline B1 & Ziban (DBM) & 10 & 0.54 & 5.97 & 2.25 .103 \\
B2 & Ziban (DBM) & 11 & 0.64 & 5.38 & 3.02 .106 \\
B3 & Ziban (DBM) & 12 & 0.6 & 5.29 & 2.40 .102 \\
B4 & Ziban (DBM) & 11 & 0.55 & 5.85 & 3.60 .102 \\
B5 & Ziban (DBM) & 7 & 0.53 & 6.15 & 1.80 .103 \\
B6 & Ziban (DBM) & 12 & 0.42 & 5.57 & 1.02 .106 \\
B7 & Ziban (DBM) & 11 & 0.6 & 5.18 & 7.102 \\
B8 & Lamghier (DBM) & 24 & 0.425 & 4.88 & 1.60 .102 \\
B9 & Adrar (UBM) & 3 & 0.65 & 5.83 & 1.75 .103 \\
B10 & Adrar (UBM) & 15 & 0.49 & 4.67 & 3.02 .106 \\
B11 & Adrar (UBM) & 8 & 0.548 & 4.77 & 3.03 .103 \\
\hline
\end{tabular}

$D B M$ direct Btana method, UBM undirected Btana method, $a w$ water activity, $P C A$ plate count agar mitochondria sequences (12,670 sequences); these were all removed from the dataset analysis (Table 2).

\section{Diversity analysis}

Clustering of the remaining 32,182 bacterial sequences (average length $479 \mathrm{bps}$ ) at $97 \%$ identity led to the identification of 606 OTUs. The rarefaction curves showed different patterns for the 11 samples, regardless of their origins (Fig. 1). The curves of the samples B3, B6, B7 (Zibane), B9, B10, and B11 (Adrar) flattened very soon after a small increase of the sequence's number, indicating that there were few OTUs in these samples. In contrast, the curves of the samples B1, B2, B4, B5 (Zibane) and B8 (Elmaghier) nver attained an asymptote phase, suggesting that the sequencing effort was too limited to obtain total diversity. On the other hand, Good's coverage at a similarity level of $97 \%$ (Table 2) was very high in all samples (98.08 to $99.91 \%$ ), indicating the detection of most of the bacterial phylotypes, with the exception of sample B5, where we found a lower coverage (76\%).

The species richness (OTU richness) observed in rarefaction curves was consistent with the diversity indices. The Chaol richness index differed significantly among the DBM samples $(P<0.05)$ but not among the UBM samples $(P>0.05)$. The Shannon diversity $(\mathrm{H})$ ranged between 0.07 and 4.77. The Simpson index revealed a significant divergence in the DBM samples $(P<0.05)$. The B1, B4, and B5 communities were remarkably evenly diverse $(0.11,0.04$, and 0.01 , respectively), but samples B3, B6 and B7 were dominated by a few phylotypes $(0.62,0.98)$ containing rare bacteria.

\section{Bacterial microflora composition of the Btana}

Taxonomic assignment of the pyrosequencing reads from the Btana samples showed good resolution at all taxonomic
Table 2 Summary of metagenomic statistics of 11 Btana samples

\begin{tabular}{|c|c|c|c|c|c|c|c|c|}
\hline \multirow[t]{2}{*}{ Sample } & \multirow{2}{*}{$\begin{array}{l}\text { Number of } \\
\text { bacterial } 16 \mathrm{~S} \\
\text { rRNA sequences }\end{array}$} & \multirow[t]{2}{*}{$\begin{array}{l}\text { Number } \\
\text { of OTUs }\end{array}$} & \multirow[t]{2}{*}{$\begin{array}{l}\text { Singleton } \\
\text { OTUs }\end{array}$} & \multicolumn{2}{|c|}{$\begin{array}{l}\text { Estimated } \\
\text { OTU richness }\end{array}$} & \multirow[t]{2}{*}{ Shannon } & \multirow[t]{2}{*}{ Simpson } & \multirow[t]{2}{*}{$\operatorname{ESC}(\%)$} \\
\hline & & & & Chaol & ACE & & & \\
\hline $\mathrm{B} 1$ & 2949 & 172 & 28 & 187 & 178 & 3.57 & 0.11 & 99.15 \\
\hline B2 & 2753 & 108 & 39 & 151 & 183 & 2.39 & 0.21 & 98.55 \\
\hline B3 & 3675 & 17 & 5 & 20 & 21 & 0.8 & 0.62 & 99.86 \\
\hline B4 & 1706 & 176 & 66 & 259 & 246 & 3.89 & 0.04 & 96.13 \\
\hline B5 & 517 & 203 & 122 & 386 & 603 & 4.77 & 0.01 & 76.74 \\
\hline B6 & 3422 & 12 & 5 & 15 & 16 & 0.07 & 0.98 & 99.85 \\
\hline B7 & 3169 & 9 & 3 & 11 & 15 & 0.35 & 0.86 & 99.91 \\
\hline B8 & 3123 & 155 & 59 & 202 & 223 & 2.47 & 0.22 & 98.08 \\
\hline B9 & 3480 & 24 & 6 & 28 & 30 & 1.83 & 0.2 & 99.8 \\
\hline B10 & 4320 & 16 & 5 & 26 & 22 & 1.34 & 0.35 & 99.88 \\
\hline B11 & 3068 & 18 & 3 & 20 & 22 & 1.74 & 0.23 & 99.87 \\
\hline
\end{tabular}

ESC estimated sample coverage (Good's coverage) 
Fig. 1 Rarefaction analysis of V1/V3 pyrosequencing reads of the bacterial 16S rRNA gene from 11 Btana samples. Rarefaction curves were constructed with a similarity cut-off value of 97 sequences.

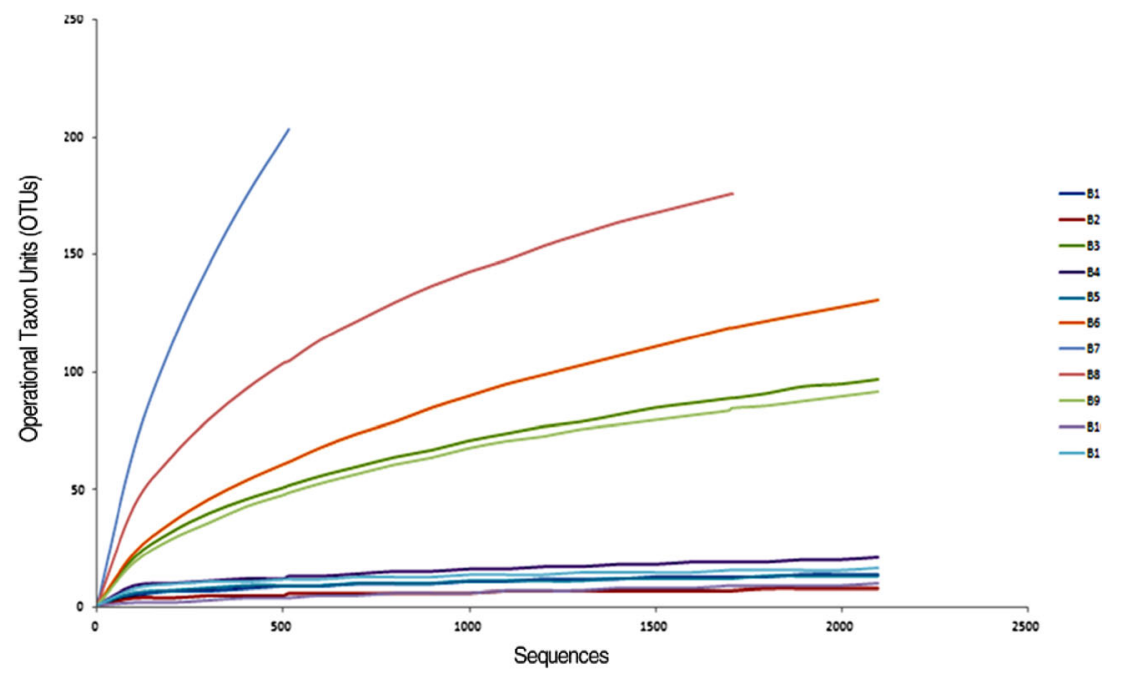

levels, and classified the indentified OTU within 8 phyla (Fig. 2). These phyla contained diverse taxonomic lineages represented by 19 classes, 33 orders, 86 families, 201 genera, and 606 species. However, only 6 OTUs had relative abundance as high as $5 \%$ of the total reads, and represented more than $63 \%$ of the total population. The subdominant subgroup (1-5\%) included 8 OTUs that represented $17.37 \%$ of the total population, while those of the rare OTUs accounted for 592 OTUs ( $97.85 \%$ of total OTUs), but surprisingly, represented a relative abundance of $19.85 \%$. We noted that of the 606 detected OTUs, 459 OTUs (75.87 \% of the total species) were detected only once in the studied samples, with 224 singleton OTUs.

Among the OTUs discovered, Firmicutes represented more than $84.79 \%$. Proteobacteria represented the next most dominant phyla (10.61\%), followed by Actinobacteria (3.01\%) and Bacteroidetes (1.14\%). Firmicutes members averaged $91.90 \% \pm 11.77 \%$ in the DBM samples (B1, B2, B3, B6, B7) and 87.42 \% \pm 17.12 $\%$ in the UBM samples. In contrast, two DBM samples (B4, B5) contained only $46.60 \%$ and $26.63 \%$ of Firmicutes, respectively. Community comparison indicates that, of the 11 samples studied, only two (B6, B8) belonging to DBM were not dominated by Bacillales. The other samples were highly dominated by Bacillales (average $90.20 \% \pm 15.12 \%$ ). Supplementary Table S1 shows the most representative OTUs detected in the Btana samples (OTUs that recorded at least a $0.1 \%$ proportion of total reads in at least one sample), and demonstrate that the Bacillus genus is the most abundant (39.53 $\%$ ), accounting for a total of 56 OTUs (results not shown). Community comparison indicated that of the 11 samples studied, only two (B6, B8) belonging to DBM were not dominated by Bacillales. The other samples were highly dominated by Bacillales (average $90.20 \% \pm 15.12 \%$ ). Supplementary Table S1 shows the most representative OTUs detected in the Btana samples (OTUs that recorded at least a $0.1 \%$ proportion of total reads in at least one sample), and demonstrates that the Bacillus genus was the most abundant (39.53\%), accounting for a total of 56 OTUs (results not shown). Bacillus megaterium was detected in all 11 samples although its distribution varied widely, and it was dominant in two Ziban DBM samples, B3 (77.06Terribacillus aidingensis was by far the predominant species in DBM sample B1, and was also identified in most other samples (0.03-29.34\%). Staphylococcus
Fig. 2 Diversity of major bacterial phyla in the 11 Btana samples

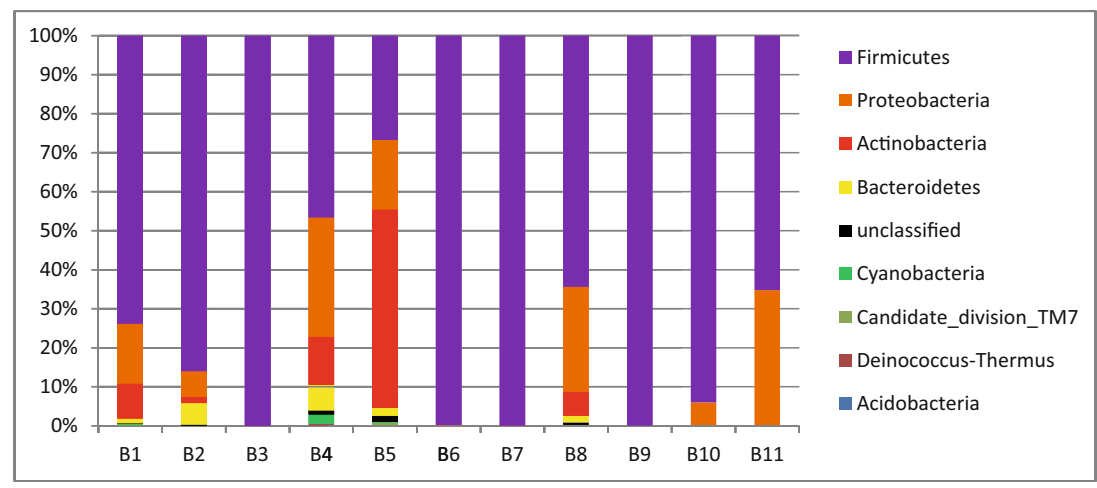


species were found in a few of the DBM and UBM samples. S. epidermidis was dominant in DBM sample B2 (41.37\%), while Staphylococcus equorum subsp. equorum was mainly detected in B11 (9.62 \%).

Diversity analysis indicated that Enterococcus was the third most frequent genus detected (16.04 \% of total OTUs). Enterococcus mundtii was the most represented species (60.69\% in the Enterococcus genus) and was dominant (99.1 \%) in DBM sample B6. In addition, DBM samples B2 and B7 and UBM sample B11 contained a relative load of Enterococcus mundtii.

Clostridiales phylotypes were primarily detected in Ziban and Elmeghier DBM samples.

Within the Proteobacteria phylum, high levels were recorded in UBM sample B11 (34.78 \%) and DBM sample B4 (30.58\%).

The Bacteroidetes were detected only in DBM samples, mainly in sample B5, which was also dominated by Actinobacteria (50.69\%). In parallel, some Corynebacterium species were found with a dominant frequency in the same sample.

\section{Comparison of the bacterial microflora of Btana from the various regions}

A Venn diagram (Fig. 3) was generated based on the origin of the samples, which showed seven OTUs (Enterococcus $s p$, Bacillus megaterium, Comamonas sp. HM.AF10, Staphylococcus epidermidis, Paracoccus sp., Staphylococcus equorum subsp. equorum, and Acidovorax JF925025) shared between DBM and UBM, accounting for $36.90 \%$ of the total sequences. Besides overlap of the species, the sequence incidence of the OTUs clearly showed that few OTUs were abundant, meaning that OTU overlap was less important. Moreover, the species were most often shared within the Btana type

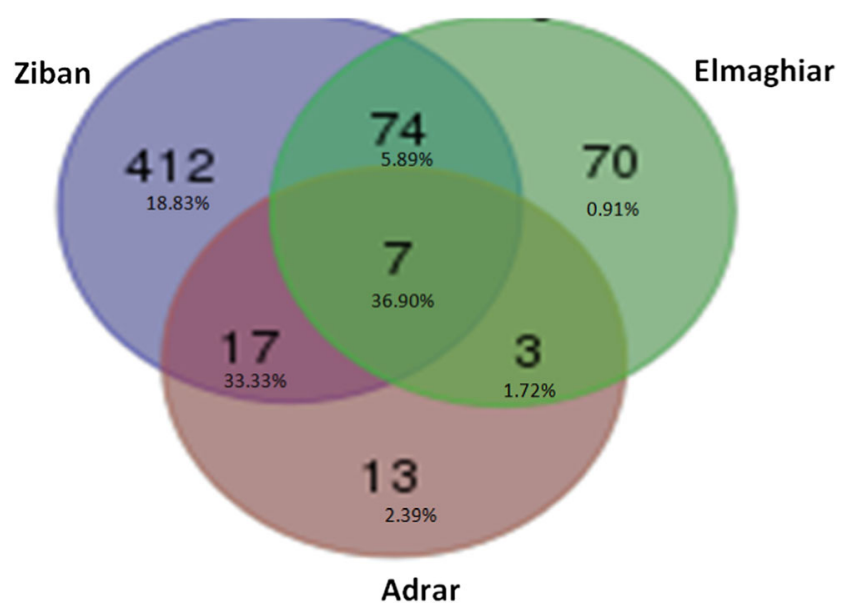

Fig. 3 Venn diagram showing OTU distribution in the Btana samples across regions
(DBM, UBM) rather than between the Btana origins. The Adrar samples produced by UBM (B9, B10 and B11) shared seven species: Bacillus safensis, Bacillus cereus, Bacillus megaterium, Paenibacillus polymyxa, Paenibacillus xylanexedens, Terribacillus aidingensis and Planomicrobium JN082684. There was a low level of specific OTUs for each sample.

Seventy four (74) OTUs overlapped between DBM samples (Ziban and Elmeghier samples), with two common species: Bacillus malacitensis and Bacillus megaterium. However, the sequence incidence of the shared OTUs was very low $(5.89 \%)$. Elmeghier sample B8 shared a total of 81 OTUs with Ziban samples, which may be partially explained by the close distance $(90 \mathrm{~km})$ between the two regions (Elmaghier and Ziban).

The weighted UniFrac test, using phylogenetic distances between randomly selected sequences, confirmed that the bacterial communities from the DBM and UBM samples were significantly different $(P<0.001$ The nMDS (Fig. 4) showed that the DBM bacterial communities were randomly scattered, with no specific influence of sample origin. In contrast, UBM samples clustered together along the first ordination axis (nMDS1). Three OTUs primarily contributed to the spatial distribution of the UBM samples: Paenibacillus polymyxa $(\mathrm{r}=0.81, P<0.01)$, Paenibacillus xylanexedens $(\mathrm{r}=0.55$, $P<0.01)$, and Planomicrobium JN082684 ( $\mathrm{r}=0.42, P<0.05)$. Some DBM samples (B2 and B4, B3 and B7) were very close to each other in the plot, suggesting similarities in bacterial community composition. Nevertheless, they differ from the other DBM samples belonging to the same region (B1, B5,

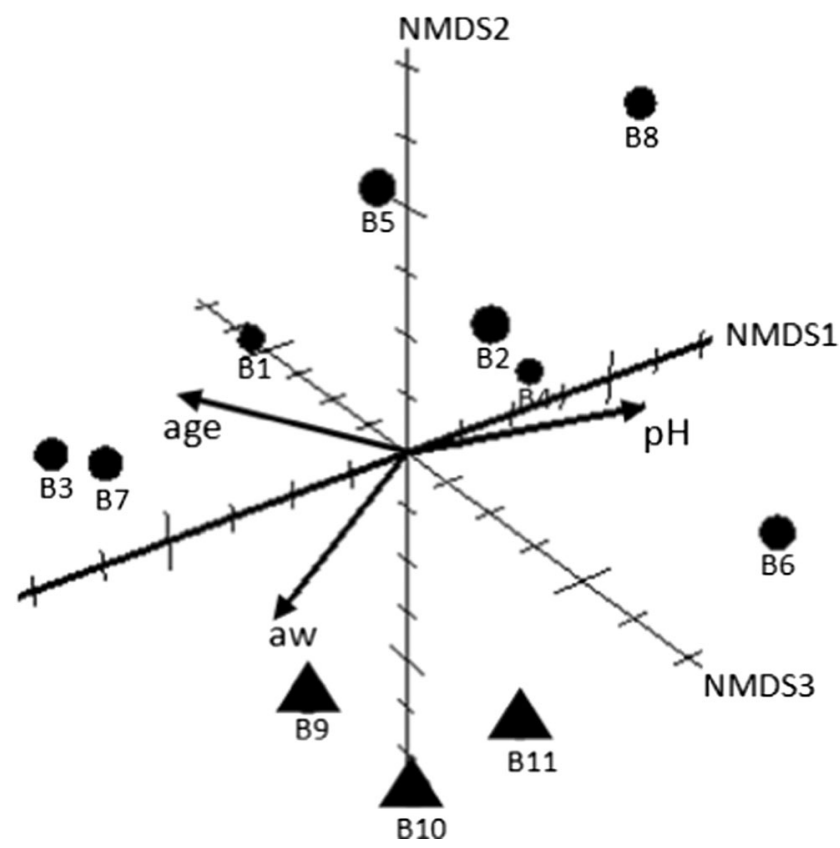

Fig. 4 Non-metric multidimensional scaling plot (nMDS) based on Bray-Curtis dissimilarity matrixes of the Btana bacterial communities (DBM samples, black triangle; UBM samples, black circle) 
B6) and from B8 (Elmeghier) prepared by the same method. The OTU network, not available in MOTHUR, was performed in the QIIME pipeline (Caporaso et al. 2010), which gives a diagram (Supplementary Fig. S2) in which each node represented either a sample or a bacterial OTU. Connections were drawn between samples and OTUs, with edge weights defined as the number of sequences from each OTU that occurred in each sample (De Filippis et al. 2013). Networks were visualized using Cytoscape 3.0. (Shannon et al., 2003). Network analysis (Fig. 6) shows a mild clustering of UBM samples; however, three DBM samples shared a number of OTUs with the UBM samples. Each Btana method had a distinct microbial core, and the number of shared species within the Btana method was very high. The number of OTUs shared among the two methods was very low, where all samples represented some unique OTUs.

\section{Discussion}

The modified CTAB method yielded much better DNA than the other methods (results not shown). Two steps may have been largely responsible for these efficiencies: treatment with the high-concentration salt solution $(5 \mathrm{M} \mathrm{NaCl})$, which separated polysaccharides from the cell extract; and BSA added during amplification, which acted as an antioxidant to eliminate residual phenols responsible for PCR inhibition (Yang et al. 2007). However, amplification of some samples was inhibited before dilution (results not shown), indicating that PCR inhibitors were not totally eliminated. The DNA quality was further enhanced by purification, leading to amplification of all DNA extracts.

The DNA extracted from the 11 Btana samples was subjected to pyrosequencing-based analysis of the 16S rRNA genes, which is a powerful and useful tool for studying the microbial diversity of a variety of traditional food items (Oguntoyinbo et al. 2007; Chao et al. 2009). To our knowledge, this is the first study investigating the microbial diversity of the traditional date product Btana using high-throughput pyrosequencing techniques. For this, a thorough study of the bacterial community was performed to gain full insight into the microbiota of this product. The high resolution of pyrosequencing was proven by the detection of several bacterial groups consistent with dominant and minor populations. Results revealed that Bacilli (Bacillaceae and Paenibacillaceae) were broadly dominant in all samples, although not all had the same sample-specific species. Bacillus and Bacillus-like bacteria were dominant in eight samples UBM, whereas Enterococcus and Staphylococcus were predominant in three DBM samples (Ziban and Elmeghier). Other major groups of bacteria were detected in the Btana as well, including Paenibacillus, Planomicrobium, and Terribacillus.
As is evident, the sole difference observed between the two Btana microbial communities is the dominance of former spore bacteria in the UBM samples, which could be due to many factors in the treatment of the date fruit during Btana preparation. Adrar Btana prepared through boiled water treatment (UBM) exhibited a common dominance of three species (Paenibacillus polymyxa, Paenibacillus xylanexedens and Planomicrobium JN082684). On the other hand, although water is added during Btana preparation, although the final aw was not higher than the DBM samples, obviously because in the Adrar region, citizens use dried date varieties like Hmira, Takarboutch and Tgaza for Btana preparation instead of the soft variety (Ghars) used in DBM (Charlery De La Masseliere 2004; Boulal et al. 2010). On the other hand, a date's chemical composition, environmental and seasonal conditions (wet or dry) and preservation period could also define the final bacterial diversity of the Btana product. Likewise, data analysis shows that bacterial communities of UBM samples are less diversified. Treatment with high-temperature water during the softening step probably eliminates a substantial portion of vegetative bacteria. In contrast, during DBM, dates are not submitted to any microbial destructive treatment, whereby the method lacks the bacterial selection effect and the initial microbiota can persist during preservation. Also, the great geographical distance between the Adrar region and the Ziban and Elmeghier regions (about $1300 \mathrm{~km}$ ) may account for the difference among the microbial communities present in the Btana. Thus, we conclude that boiled water treatment reduces most of the vegetative bacteria, while, on the other hand, some species like Terribacillus aidingensis, Bacillus malacitensis, Bacillus safensis, Acidovorax JF925025, and Comamonas sp. HM AF10 were detected in almost all Btana samples regardless of its type, indicating a possible adaptation to the Btana product. In the cases of species being found unequally in the Btana product, it is most likely attributable to environmental contaminants. Generally, Btana is prepared in open air places that facilitate catching of such types of bacteria. Raw dates can also function as a potent vehicle for some plant-originated bacteria such as Enterococcus mundtii (Collins et al. 1986) and the human skin bacteria Staphylococcus epidermidis that might be transferred to Btana during manual. The common features of these bacteria are their environmental origin, facultative anaerobic mode of nutrition and osmotolerant ability (De Vos et al. 2009). Bacterial microflora was found on the outer surface of most dates because of it being spread by wind, rain, and water flux, etc. Whereas, amalgamation of dates during Btana preparation enhances microbial distribution and further modifies its parameters such as oxygen availability, $\mathrm{pH}$ and aw, on other hand, the development of strictly aerobic bacteria in Btana would have been inhibited because of the low oxygen availability which affects their tolerance to non-ideal pH and aw conditions (Mossell 1975). Hence, the majority of the observed species in microflora of the Btana are facultative anaerobes. Unlike the majority of fermented 
foods dominated by Lactobacillus (LAB), Bacillus sps. were implicated in fermentation of traditional foods based on leaves, seeds and seafood in Africa (Okpehe: Oguntoyinbo et al. 2007; Hawaijar: Jeyaram et al. 2008; Jeotgal: Guan et al. 2011). Moreover, Bacillus species were also isolated from similarly high osmopressure food items like honey (Iurlina and Fritz 2005). Similarly, Btana has high osmopressure resulting from the high sugar content in dates (Vayalil 2012). Grant (2004) revealed that high-sugar foods (with low aw) are mainly dominated by xerophilic fungi and osmophilic yeasts. However, the presence of halotolerant bacteria in these foods was often reported, although the osmotic stress imposed by cations (salts) and uncharged organic solutes (like sucrose) is not the same (Williams and Hallsworth 2009). Recently, a halotolerant bacterium Tetragenococcus halophilus was found to be dominant (>99 \%) in a high-sugar "thick juice" (Justé et al. 2008). Thus, it is expected that one would find many halotolerant bacteria in Btana samples, such as: Corynebacterium, Acinetobacter, Acidovorax, Propionibacterium, Staphylococcus and Peptostreptococcus (De Vos et al. 2009). Moreover, osmotolerance is linked with the availability of osmoprotectants in the surrounding medium to help bacteria to maintain the internal homeostasis (Williams and Hallsworth 2009). Interestingly, it was reported that dates are very rich in proline (12-369 mg/100 g), choline (6.30-9.90 mg/100 g), betaine $(0.4 \mathrm{mg} / 100 \mathrm{~g})$, and also contain a high level of potassium $(703-1130 \mathrm{mg} / 100 \mathrm{~g})$ (Favier et al. 1993; Al-Shahib and Marshall 2002; El-Sohaimy and Hafez 2010; Kchaou et al. 2013). The uptake of the aforementioned compounds plays a key role in cellular adaptation to a hypertonic environment, thus permitting some bacterial groups to survive the osmotic conditions of the Btana (Vilhelmson and Miller 2002). However, our molecular approach based on $16 \mathrm{~s}$ RNA genes as the template does not exclusively select active bacteria, as dead and damaged cell can. Also, the presence of vegetative aerobic bacteria such as Kocuria, Acinetobacter GQ096364, Acinetobacter junii and Acidovorax JF925025 should be investigated if no recent contamination from a secondary source is expected. Generally, Btana is prepared in open air places that facilitate catching of such types of bacteria. Raw dates could also represent a potent vehicle of some plant-originated bacteria such as Enterococcus mundtii (Collins et al. 1986). Also, Staphylococcus epidermidis inhabiting human skin may be transferred to Btana during manual preparation.

The detection of a low number of pathogenic bacteria were reported in some samples (B1: Staphylococcus aureus; B2: Clostridium GQ158426, Bacillus cereus; B3: C. botulinum; B4 and B5: Kocuria palustris) underlines the need for stricter hygiene during Btana preparation. Also, further investigation is needed to examine the viability of these bacteria because pyrosequencing analysis is a semi-quantitative technique that does not verify the viability of the detected microorganisms, in particular, for the spore bacteria (Amend et al. 2010).
Moreover, we should use specific nucleic acid extraction tools such as those targeting RNA or cDNA, that exclusively select active microbial populations (De Pasquale et al. 2014).

\section{Conclusions}

It is well established that high-quality NGS analysis for the accurate study of microbial diversity requires optimal DNA extraction. Here, using the classic CTAB method, we have succeeded in isolating a good DNA yield suitable for further molecular analysis from the traditional date product Btana. Results obtained from the 16S rRNA-targeted metagenomic analysis give us a more detailed view of the bacterial communities in Btana and also show high prevalence of the sporeforming Bacillus and its relatives. This study also revealed that the culturing-dependent methods are still important for studying the viable organisms, and are appropriate for investigating bacterial adaptation to osmotic stresses. Preparation of Btana influences the microbial diversity, owing to hot water treatment applied during the UBM that leads to a substantial reduction in the bacterial load in the Btana product. Moreover, Btana produced by the DBM is more susceptible to Enterococcus and Staphylococcus growth in comparison with the UBM. It is noteworthy to point out that this investigation was performed on random samples; therefore, future studies should standardize the Btana characteristics for more accurate comparison to avoid variation associated with the sampling plan. Beside this, more attention should be paid to bacterial functionality and to the other microbial groups (yeasts) in development of the product characteristics.

\section{References}

Abekhti A, Zarour K, Boulal A, Benmechernene Z, Kihal M (2013) Evaluation of microbiological quality of the date fruit product "btana" produced in Adrar South Algeria. J Microbiol Res 3(5): $163-170$

Al-Shahib W, Marshall RJ (2002) Dietary fiber content of 13 varieties of date palm (phoenix dactylifera L). J Food Sci Tech 37:719-721

Amend AS, Seifert KA, Bruns TD (2010) Quantifying microbial communities with 454 pyrosequencing: does read abundance count? Mol Ecol 19:5555-5565

Bonomo MG, Salzano G, Ricciardi A (2010) Influence of autochthonous starter cultures on microbial dynamics and chemical-physical features of traditional fermented sausages of Basilicata region. World $\mathrm{J}$ Microbiol Biotechnol 27(1):137-146

Boudries H, Panagiotis K, Damaso HM (2007) Carotenoid composition of Algerian date varieties at different edible maturation stages. Food Chem 101:1372-1377

Boulal A, Benali B, Moulai M, Touzi A (2010) Transformation des déchets de dattes de la région d'Adrar en bioéthanol. Rev Energ Renouv 13(3):455-463 
Brosius J, Ullrich A, Raker MA, Gray A, Dull TJ, Gutell RR, Noller HF (1981) Construction and fine mapping of recombinant plasmids containing the rrnB ribosomal RLNA operon of E. coli. Plasmid 6: $112-118$

Caporaso KJ, Stombaugh J, Bittinger K, Bushman FD, Costello EK, Fierer N, Pena AG, Goodrich JK, Gordon JI, Huttley GA, Kelley ST, Knights D, Koenig JE, Ley RE, Lozupone CA, McDonald D, Muegge BD, Pirrung M, Reeder J, Sevinsky JR, Turnbaugh PJ, Walters WA, Widmann J, Yatsunenko T, Zanefeld J, Knight R (2010) QIIME allows analysis of high-throughput community sequencing data. Nat Methods 7:335-336

Chang YC, Wang JY, Selvam A, Kao SC, Yang SS, Shih DYC (2008) Multiplex PCR detection of enterotoxin genes in Aeromonas spp, from suspect food samples in Northern Taiwan. J Food Prot 71: 2094-2099

Chao A, Bunge J (2002) Estimating the number of species in a stochastic abundance model. Biometrics 58:531-539

Chao A, Colwell RK, Lin CW, Gotelli NJ (2009) Sufficient sampling for asymptotic minimum species richness estimators. Ecology 90: $1125-1133$

Charlery De La Masseliere B (2004) Fruits des terroirs fruits défendus. Identités Mémoires et Territoires, Presses universitaires du Mirail, Toulouse

Collins MD, Farrow JAE, Jones D (1986) Enterococcus mundtii sp, nov. Int J Syst Bacteriol 36:8-12

Colwell RK, Coddington JA (1994) Estimating terrestrial biodiversity through extrapolation. Philos Trans Roy Soc London 345:101-118

De Filippis F, La Storia A, Villani F, Ercolini D (2013) Exploring the sources of bacterial spoilers in beefsteaks by culture-independent high-throughput sequencing. PLoS One 8, e70222

De Pasquale I, Di Cagno R, Buchin S, De Angelis M, Gobbetti M (2014) Microbial ecology dynamics reveal a succession in the core microbiota involved in the ripening of pasta filata caciocavallo pugliese cheese. Appl Environ Microbiol 80:6243-6255

Delcenserie V, Taminiau B, Delhalle L, Nezer C, Doyen P, Crevecoeur S, Roussey D, Korsak N, Daube G (2014) Microbiota characterization of a Belgian protected designation of origin cheese, Herve cheese, using metagenomic analysis. J Dairy Sci 97:1-11

De Vos P, Garrity G, Dorothy J, Krieg NR, Ludwig W, Rainey FA, Schleifer KH, Whitman WB (2009) Bergey's Manual of Systematic Bacteriology: Volume 3: The Firmicutes, Springer.

El-Sohaimy SA, Hafez EE (2010) Biochemical and nutritional characterizations of date palm fruits (Phoenix dactylifera L,). J Appl Sci Res 8:1060-1067

Favier JC, Ireland RJ, Laussucq C, Feinberg M (1993) Répertoire général des aliments, Table de composition des fruits exotiques fruits de cueillette d'Afrique. Tome III Ed, ORSTOM Lavoisier, INRA

Good IJ (1953) The population frequencies of species and the estimation of population parameters. Biometrika 40(3-4):237-264

Grant WD (2004) Life at low water activity. Philos Trans Roy Soc London 359:1249-1266

Greppi A, Rantsiou K, Padonou HJ, Jespersen J, Jakobsen M, Cocolin M (2013) Determination of yeast diversity in ogi mawè gowé and tchoukoutou by using culture-dependent and -independent methods. Int J Food Microbiol 165:84-88

Guan L, Cho KH, Lee JH (2011) Analysis of the cultivable bacterial community in Jeotgal a Korean salted and fermented seafood and identification of its dominant bacteria. Int J Food Microbiol 28:101113

Haas BJ, Gevers D, Earl AM, Feldgarden M, Ward DV, Giannoukos G, Ciulla D, Tabbaa D, Highlander SK, Sodergren E, Methe B, Desantis TZ, Petrosino JF, Knight R, Birren BW (2011) Chimeric 16S rRNA sequence formation and detection in Sanger and 454pyrosequenced PCR amplicons. Genome Res 21:494-504
Iurlina MO, Fritz R (2005) Characterization of microorganisms in Argentinean honeys from different sources. Int J Food Microbiol 105:297-304

Jeyaram K, Mohendro W, Singh T, Premarani A, Ranjita Devi K, Selina Chanu N, Talukdar C, Rohinikumar Singh M (2008) Molecular identification of dominant microflora associated with Hawaijar: a traditional fermented soybean food of Manipur India. Int J Food Microbiol 122:259-268

Justé A, Lievens B, Frans I, Klingeberg M, Michiels CW, Willems KA (2008) Present knowledge of the bacterial microflora in the extreme environment of sugar thick juice food. Microbiology $25: 831-836$

Kchaou W, Abbès F, Blecker C, Attia H, Besbes S (2013) Effects of extraction solvents on phenolic contents and antioxidant activities of Tunisian date varieties (Phoenix dactylifera L,). Ind Crops Prod 45:262-269. Ind Crops Prod

Mossell DAA (1975) Water and micro-organisms in foods a synthesis, In Duckworth RB (Ed). Water Relations of Foods: Academic Press London. pp. 347-61

Mukisa IM, Muyanja CMBK, Byaruhanga YB, Schüller RB, Langsrud T, Narvhus JA (2012) Gamma irradiation of sorghum flour: effects on microbial inactivation amylase activity fermentability viscosity and starch granule structure. Radiat Phys Chem 81:345-351

Northolt MD, Frisvad JC and RA Samson Occurrence of food-borne fungi and factors for growth. In: RA Samson (Ed). Introduction to Food-Borne Fungi. Baarn : Centraalbureau voor Schimmelcultures, 1995: 243-250

Obadina AO, Oyewole OB, Odusami AO (2009) Microbiological safety and quality assessment of some fermented cassava products (lafun, fufu, gari). Sci Res Essays 4(5):432-435

Oguntoyinbo FA, Narbad A (2012) Molecular characterization of lactic acid bacteria and in situ amylase expression during traditional fermentation of cereal foods. Food Microbiol 31:254-262

Oguntoyinbo FA, Sanni AI, Franz CMAP, Holzapfel WH (2007) Phenotypic diversity and technological properties of Bacillus subtilis species isolated from Okpehe a traditional fermented condiment. World J Microbiol Biotechnol 23:401-410

Oguntoyinbo FA, Tourlomousis P, Gasson MJ, Narbad A (2011) Analysis of bacterial communities of traditional fermented west African cereal foods using culture independent methods. Int J Food Microbiol 145:205-210

Probeski S, Bailey LG, Baum BR (1997) Modification of a CTAB DNA extraction protocol for plants containing high polysaccharide and polyphenol components. Plant Mol Biol 15:8-15

Pruesse E, Quast C, Knittel K, Fuchs (2007) SILVA: A comprehensive online resource for quality checked and aligned ribosomal RNA sequence data compatible with ARB. Nucleic Acids Res 35:71887196

Quince C, Lanzen A, Curtis TP (2009) Accurate determination of microbial diversity from 454 pyrosequencing data. Nat Methods 6:639641

Sánchez-Hernández C, Gaytán-Oyarzún JC (2006) Two mini-preparation protocols to DNA extraction from plants with high polysaccharide and secondary metabolites. Afr J Biotechnol 5(20):1864-1867

Schloss PD, Westcott T, Ryabin JR, Hall JR, Hartmann M, Hollister EB, Lesniewski RA, Oakley BB, Parks DH, Robinson CJ, Sahl JW, Stres B, Thallinger GG, Van Horn DJ, Weber CF (2009) Introducing mothur: open-source platform-independent community-supported software for describing and comparing microbial communities. Appl Envir Microbiol 75(23):7537-7541

Schoustra SE, Kasase C, Toarta C, Kassen R, Poulain AJ (2013) Microbial community structure of three traditional Zambian fermented products: mabisi chibwantu and munkoyo. PLoS ONE 8(5), e63948. doi:10.1371/journal.pone.0063948 
Shannon CE, Weaver W (1963) The mathematical theory of communication. University of Illinois Urbana

Thakuria D, Schmidt O, Mac Siúrtáin M, Egan D, Doohan FM (2008) Importance of DNA quality in comparative soil microbial community structure analyses. Soil Biol Bioch 40: $1390-1403$

Vayalil PK (2012) Date fruits (Phoenix dactylifera Linn): an emerging medicinal food. Critical Rev Food Sci Nut 52:249-271
Vilhelmson O, Miller K (2002) Humectant permeability influences growth and compatible solute uptake by Staphylococcis aureus subjected to osmotic stress. J Food Prot 65(6):1008-15

Williams JP, Hallsworth JE (2009) Limits of life in hostile environments: no barriers to biosphere function? Envir Microbiol 11:3292-3308

Yang ZH, Xiao Y, Zeng GM, Xu ZY, Liu YS (2007) Comparison of methods for total community DNA extraction and purification from compost. Appl Microbiol Biotec 74:918-925 